Case Report

\title{
Amlodipine drug therapeutic failure: a rare case report
}

\author{
Kandarp K. Thakkar, Kartik Shah*, Devang Rana, Supriya D. Malhotra, Pankaj R. Patel
}

Department of Pharmacology, Smt. NHLMMC, Ahmedabad, Gujarat, India

Received: 07 November 2017 Accepted: 28 November 2017

\section{*Correspondence to: \\ Dr. Kartik Shah, \\ Email: knshah10@gmail.com}

Copyright: (C) the author(s), publisher and licensee Medip Academy. This is an openaccess article distributed under the terms of the Creative Commons Attribution NonCommercial License, which permits unrestricted noncommercial use, distribution, and reproduction in any medium, provided the original work is properly cited.

\begin{abstract}
Drug Therapeutic failure is a rare condition which is underreported in recent scenario. It is important for the chronic diseases like Hypertension where it could lead to fatal outcome. In our case report elderly male patient taking tablet Amlodipine once daily as antihypertensive medication and had 2 years without any events. Patient came to the emergency department with the complaint of altered sensorium and elevated blood pressure. The mechanism for sudden increase in blood pressure (Decreased Therapeutic Response) in patient with ongoing treatment with amlodipine could be due to sympathetic over activity (e.g. stress), pharmacokinetic variation or counterfeit drug.
\end{abstract}

Keywords: Amlodipine, Drug therapeutic failure, Hypertension, Pharmacovigilance

\section{INTRODUCTION}

The potential causes of drug therapeutic failure depend upon influence of several factors including Medical, Environmental and Social factors for example inappropriate drug selection or dosage, an adulterated or a fake drug, wrong diagnosis by consulting physician, patient's non-adherence towards medicines. The other factors for drug therapeutic failure can be poor bioavailability of the drug or lack of efficacy, medication error, or an adverse drug reaction. Failures can occur at any step of the therapeutic chain, which is the process describing the life of medicines in a community. ${ }^{1,2}$

Drug therapy with calcium channel blocker (CCB) is one of the pillars in the management of hypertension. ${ }^{3}$ Among the CCBs the prototype drug amlodipine is one of the most prescribed antihypertensive drugs worldwide. ${ }^{4,5}$ Drug resistances is found among people who take Amlodipine, especially for people who are more than 60 years old male. The review analyzes which people have Drug resistance with Amlodipine, based on reports of 25,112 people who have side effects when taking Amlodipine. As reported by FDA, Amlodipine has various known side effect but report of therapeutic failure is less documented $(0.31 \%){ }^{6}$

\section{CASE REPORT}

Case history was taken on $29^{\text {th }}$ September 2016.

A 65-year-old male patient came to the Emergency Department on $20^{\text {th }}$ September 2016 with the complaint of altered sensorium for 1 day. On examination patient had elevated blood pressure (BP) 188/100mmHg, rest all vitals were within normal limit. Patient had normal sinus rhythm on ECG and no signs of Infarction found on ECG and Blood analysis. CT (Computed Tomography) scan brain did not suggest any intracranial haemorrhage or any other 
abnormality. Patient's complete blood analysis was found to be normal including Renal Function Test. Patient was treated in emergency department with Injection Labetalol $4 \mathrm{ml}(20 \mathrm{mg})$ i.v. stat for duration of 2 minutes. Patient was a known case of Hypertension and was taking Tablet Amlodipine (5mg) 1 tablet once daily for 2 years. Patient had undergone BP measurement before one month by a general practitioner and as reported by patient his BP reading was $128 / 86 \mathrm{mmHg}$. Patient was taking medicine regularly and was uneventful till $19^{\text {th }}$ September 2016. Two days after admission his raised BP was controlled and was within normal limits. Patient was not on any Over the Counter (OTC) medication for cough and cold and did not take any allopathic or herbal medications at the time of presentation to the Emergency Medicine department. This case was reported to the nearest Pharmacovigilance centre under PVPI (Pharmacovigilance Programme of India) with the report ID-2016-50955.

Causality assessment as per WHO (World Health Organisation): Possible.

\section{DISCUSSION}

Hypertension is a multifactorial disease which is affected by several closely related factors for example genetic, environmental etc. Specifically, genetic factors can influence blood pressure elevation by $30-50 \% .^{7}$ Calcium channel blockers bind to L-type calcium channels located on the vascular smooth muscle and cardiac tissue which leads to influx of calcium into muscle cells, which in turn stimulates smooth muscle contraction and cardiac myocyte contraction. Calcium channel blockers causes vasodilatation and decrease systemic vascular resistance, which lowers arterial blood pressure.

In our case report patient was taking tablet Amlodipine 5 mg once daily for the last 2 years. Patient was compliant to the treatment and was taking medication without changing dosage or forgetting to take medicine. Patient was uneventful for the last 2 years as his BP was in control and he had no complaint of any illness during this period. He regularly came for visits and did not change the brandname of the medication as he only took medicine supplied in the hospital medicine dispensing unit. However we cannot rule out the possibilities of counterfeit drug in concern with amlodipine tablet.

Patient did not have any history of emotional stress or physical stress near a month of the event or he was not on any other medication which can cause Drug-Drug Interaction with the Amlodipine. We also cannot rule out the possibility of altered pathological state in this patient at the time of presentation in emergency department.

Drug therapeutic failure (DTF) is considered as an adverse drug reaction (ADR) in which the expected drug effects don't occur as per prescribed treatment, which includes any clinical event which is related to a low prescribed dose or lack of compliance. DTFs are responsible for increasing disease length, hospitalization time and costs, with the worsening of patients' quality of life. ${ }^{8}$

Reasons of drug therapeutic failure due to Amlodipine could be genetic variation in individual which leads to failure of the drug response or it could be altered pharmacokinetic in the individual as patient is elder and at pharmacokinetic values changes in elderly. Data have suggested that CYP3A5 and ABCB1(ATP Binding Cassette Subfamily B Member 1) gene polymorphisms are associated with increased blood pressure in the rat as well as in humans and the effects of these genes on blood pressure appear to be modified by dietary salt intake. ${ }^{9}$ However study by Chengxian et al reveals that genetic polymorphism of MDR1 ( multidrug resistance protein 1) $\mathrm{C} 3435 \mathrm{~T}$ and gender had a certain effect on plasma concentration of amlodipine but did not affect its antihypertensive efficacy thus genetic polymorphism of MDR1 had an effect on amlodipine pharmacokinetics but there was no influence on amlodipine pharmacodynamics. ${ }^{10}$

High Salt intake exacerbates BP elevation during the development of hypertension in SHR (Spontaneously Hypertensive Rats) by activation of the sympathetic nervous system via an increase in ROS (reactive oxygen species) generation, probably due to activation of the AT1R/NAD (P) $\mathrm{H}$ oxidase pathways. ${ }^{11}$ It is being hypothesized that changes in humoral or immunological factors may lead to systemic vasoconstriction and increase in vascular resistance which leads to elevation in blood pressure. High BP causes shear stress and endothelial injury leading to further aggravating of blood pressure. ${ }^{12}$

A meta-analysis of more than 40 studies has shown that combining two agents from any two classes of antihypertensive drugs increases the BP reduction much more than increasing the dose of one agent. And guidelines from the European Society of Hypertension/European Society of Cardiology (ESH/ESC) emphasizes that the ability of any antihypertensive agent used alone to achieve target BP values (<140/90 mm Hg) does not exceed $20 \%$ to $30 \%$ of the overall hypertensive population except in patients with grade 1 hypertension. ${ }^{13,14}$

\section{CONCLUSION}

Drug Therapeutic failure is a rare condition which is underreported in recent scenario. The mechanism for sudden increase in blood pressure (Decreased Therapeutic Response) in patient with ongoing treatment with amlodipine could be due to sympathetic over activity (e.g. stress), pharmacokinetic variation or counterfeit drug.

\section{ACKNOWLEDGEMENTS}

Authors would like to thank Dr. Pankaj R. Patel, Professor and Dean, Smt. N.H.L. Municipal Medical College, Ahmedabad for his guidance and support. Also they would 
like to thank the professors and residents of the Emergency Department for guiding and helping them with this case.

Funding: No funding sources

Conflict of interest: None declared

Ethical approval: Not required

\section{REFERENCES}

1. World Health Organization Expert Committee. WHO model list of essential medicines: $12^{\text {th }}$ list. Geneva: WHO, April 2002. Available at: Who.int/ medicines/organization/par/edl/ed12002core.pdf

2. Figueras A, Laporte JR. Failures of the therapeutic chain as a cause of drug ineffectiveness: Promotion, misinformation, and economics work better than needs. BMJ: British Medical J. 2003;326(7395):8956.

3. James PA, Oparil S, Carter BL, Cushman WC, Dennison-Himmelfarb C, Handler J, et al. EvidenceBased Guideline for the Management of High Blood Pressure in Adults Report From the Panel Members Appointed to the Eighth Joint National Committee (JNC 8). JAMA. 2014;311(5):507-20.

4. Toupance O, Lavaud S, Canivet E. Antihypertensive effect of amlodipine and lack of interference with cyclosporine metabolism in renal transplant recipients. Hypertension. 1994 Sep;24:297-300.

5. Naidu MUR, Usha PR, Rao TRK. Evaluation of amlodipine, lisinopril, and a combination in the treatment of essential hypertension Postgraduate Medical J. 2000;76:350-3.

6. Amlodipine besylate and Therapeutic response decreased - from FDA reports. Available at: http://www.ehealthme.com/ds/amlodipinebesylate/therapeutic-response-decreased/ (accessed on 01 February 2017 \& 13 July 2017).

7. Dominiczak AF, Negrin DC, Clark JS, Brosnan MJ, mcbride MW, Alexander MY. Genes and hypertension: from gene mapping in experimental models to vascular gene transfer strategies. Hypertension. 2000;35:164-72.

8. Franceschi A, Tuccori M, Bocci G, Vannozzi F, Di Paolo A, Barbara C, et al. Drug therapeutic failures in emergency department patients. A university hospital experience. Pharmacol Res. 2004;49:85-91.

9. Bochud $\mathrm{CB}$, Elston $\mathrm{M}$, Bovet RC, Maillard $\mathrm{P}$, Nussberger NP, Schild J, et al. CYP3A5 and ABCB1 genes influence blood pressure and response to treatment, and their effect is modified by salt. / Eap, In: Hypertension. 2007;49(5):1007-14.

10. Guo, Chengxian. Effects of Genetic Factors on the Pharmacokinetics and Pharmacodynamics of Amlodipine in Primary Hypertensive Patients. Biomedical Reports. 2015;3(2):195-200. PMC. Web. 19 July 2017.

11. Koga Y, Hirooka Y, Araki S, Nozoe M, Kishi T, Sunagawa K. High salt intake enhances blood pressure increase during development of hypertension via oxidative stress in rostral ventrolateral medulla of spontaneously hypertensive rats. Hypertension Research. 2008 Nov 1;31(11):2075-83.

12. Rafey MA. Resistant hypertension in the elderly. Clinics in Geriatric Medicine. 2009;25(2):289-301.

13. Wald DS, Law M, Morris JK, Bestwick JP, Wald NJ. Combination therapy vs. monotherapy in reducing blood pressure: meta-analysis on 11,000 participants from 42 trials. Am J Med. 2009;122:290-300.

14. Mancia G, Fagard R, Narkiewicz K. ESH/ESC guidelines for the management of arterial hypertension: The Task Force for the Management of Arterial Hypertension of the European Society of Hypertension (ESH) and of the European Society of Cardiology (ESC). Eur Heart J. 2013;34(28):2159219.

Cite this article as: Thakkar KK, Shah K, Rana D, Malhotra SD, Patel PR. Amlodipine drug therapeutic failure: a rare case report. Int J Basic Clin Pharmacol 2018;7:203-5. 